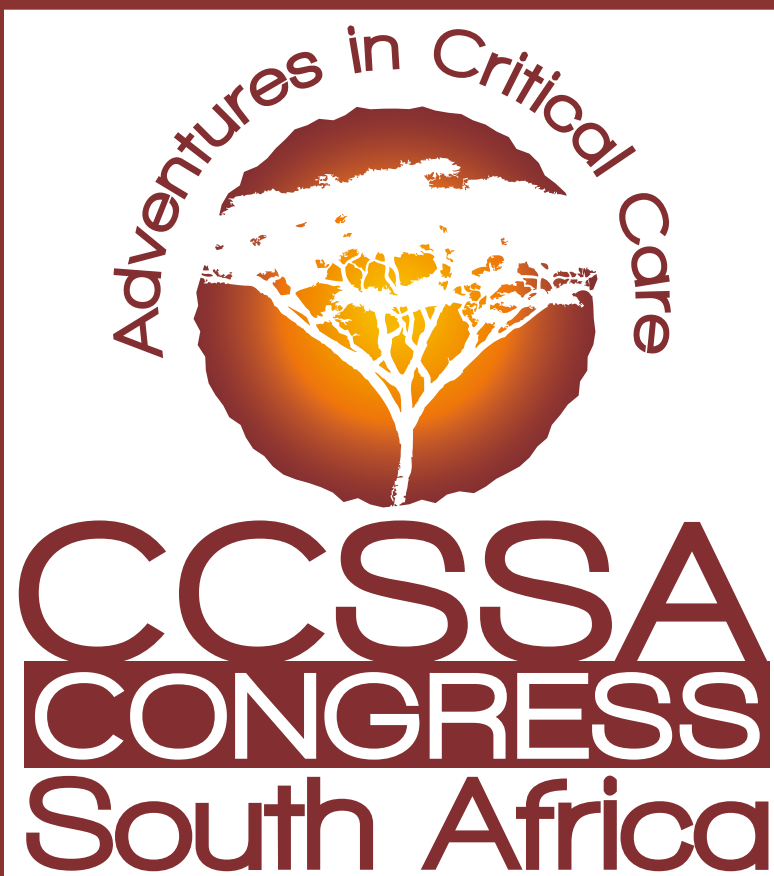

9 - 12 July 2015

www.criticalcare.org.za

Europa Organisation Africa

Tel No. + 27 (0)11 325 0020/22/23

Enquiries and assistance:

www.eoafrica.co.za or

email mandy@eoafrica.co.za

Sun City I North West Province

\title{
Variations in endotracheal tube cuff pressure: Is 8-hourly monitoring enough?
}

M E Memela, ${ }^{1}$ MTech Clinical Technology; P D Gopalan, ${ }^{2}$ MB ChB, FCA (SA), Crit Care (SA)

Department of Biomedical and Clinical Technology, Durban University of Technology, KwaZulu-Natal, South Africa

${ }^{2}$ Department of Anaesthesiology and Critical Care, Nelson R Mandela School of Medicine, Durban, KwaZulu-Natal, South Africa

Corresponding author:M EMemela (memelame@dut.ac.za)

Background. Most patients admitted to an intensive care unit (ICU) for mechanical ventilation require endotracheal intubation. Cuffed endotracheal tubes (ETTs) are utilised as they provide a better seal to facilitate ventilation and minimise aspiration. Complications due to overinflation or underinflation of the cuff may occur. Neither the frequency of intermittent cuff pressure (Pcuff) measurement nor the advantage of continuous Pcuff monitoring has been clearly established.

Objective. To determine deviations in ETT Pcuff from the recommended range during the intervals between routine thrice-daily Pcuff measurements in adult ICU patients. Our key objective was to identify the extent and cause of ETT Pcuff changes during these intervals. In addition, we attempted to demonstrate the failure of routine thrice-daily Pcuff monitoring to detect the large variation in Pcuff of patients throughout the day.

Methods. This prospective, observational study was conducted in the King Edward VIII Hospital ICU, Durban, KwaZulu-Natal Province, South Africa. Ethical and institutional approval was obtained. Consent was obtained from patients' next of kin. Intermittent Pcuff was recorded using mechanical manometers, and continuous measurements using pressure transducers.

Results. Thirty-five critically ill adult patients were enrolled. The mean study time was $11.1 \mathrm{~h}$. The mean Pcuff was 25.6 (standard deviation 7.1) $\mathrm{cmH}_{2} \mathrm{O}$ for the intermittent group and 26.6 (8.7) $\mathrm{cmH}_{2} \mathrm{O}$ for the continuous group. The intermittent pressure measurements were in the low-pressure range $\left(<20 \mathrm{cmH}_{2} \mathrm{O}\right) 12 \%$ of the time compared with $83 \%$ in the target pressure range $\left(20-30 \mathrm{cmH}_{2} \mathrm{O}\right)$ and $5 \%$ in the high-pressure range $\left(>30 \mathrm{cmH}_{2} \mathrm{O}\right)$. For continuous pressures, $13 \%$ of the time was spent in the low-pressure range, $64 \%$ in the target pressure range, and $23 \%$ in the high-pressure range. For the entire study, 588 events causing Pcuff alterations were recorded. Conclusion. Continuous monitoring of Pcuff indicated that the endotracheal Pcuff varied extensively during mechanical ventilation in critically ill patients, such variation being noted both between patients and within individual patients. Variations in individual patients occurred both during intrinsic patient activities and those of ICU personnel as part of routine patient maintenance. Intermittent monitoring may not detect these variations. Continuous monitoring of Pcuff during mechanical ventilation in ICUs is thus recommended for all patients. 


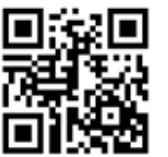

Most patients admitted to an intensive care unit (ICU) for mechanical ventilation require endotracheal intubation. Endotracheal tubes

(ETTs) with cuffs are utilised as they provide a better seal to facilitate ventilation and minimise aspiration. ${ }^{[1,2]}$ The cuff pressure (Pcuff) must be maintained within a target range that is adequate to ensure effective mechanical ventilation and prevent pulmonary aspiration, yet low enough to prevent compression of tracheal capillaries. ${ }^{[1]}$ Several complications due to the Pcuff exerted on the tracheal mucosa have been identified. ${ }^{[3]}$ Overinflation may cause partial or total obstruction of tracheal mucosal blood flow, resulting in tracheal necrosis leading to tracheal stenosis and granulomas, and rarely - but catastrophically - rupture of the trachea. ${ }^{[46]}$ The close proximity of the oesophagus posteriorly, combined with the presence of, for example, a nasogastric tube, may lead to the formation of tracheooesophageal fistulas. ${ }^{[7]}$ Underinflation may cause air leakage, resulting in inadequate ventilation and an increased risk of aspiration. ${ }^{[8,9]}$ In addition, ETT Pcuff may change radically owing to various factors that exert effects on the cuff. Such factors include patient airway suctioning, coughing, struggling, neck movements, modes of ventilation and temperature. ${ }^{[10-12]}$ Therefore, it is vitally important that Pcuff is diligently maintained within the recommended range.

The ideal range for Pcuff remains contentious. Most studies recommend that Pcuffs be maintained between $20 \mathrm{cmH}_{2} \mathrm{O}$ and $30 \mathrm{cmH}_{2} \mathrm{O}^{[13-15]}$ However, some researchers argue that monitoring Pcuff alone is insufficient because tracheal damage may occur even in ideal ranges. ${ }^{[13,16,17]}$ Many researchers have also questioned the value of intermittent monitoring as this often misses many episodes of Pcuff changes. ${ }^{[16-19]}$ Continuous monitoring has therefore been advocated as an alternative. Sole et al. ${ }^{[20,21]}$ validated a method of continuous Pcuff measurement. Subsequently, continuous Pcuff monitoring was shown to be advantageous. ${ }^{[2,22]}$ However, continuous monitoring itself may present potential problems, e.g. there may be an increased cost and risk of infection. The added attachments may hinder patient mobilisation and increase the risk of tube disconnection and cuff deflation with aspiration.

\section{Objective}

The objective of this study was to determine deviations in ETT Pcuff from the recommended range during the intervals between routine thrice-daily Pcuff measurements in adult ICU patients. A key objective was to identify the extent and cause of ETT Pcuff changes during these intervals. In addition, we attempted to demonstrate the failure of routine thrice- daily Pcuff monitoring to detect the large variation in Pcuff of patients throughout the day.

\section{Methods}

This was a prospective, observational study conducted in the King Edward VIII Hospital ICU, Durban, KwaZulu-Natal Province, South Africa. Ethical and institutional approval was obtained. All patients admitted to

Table 1. Intermittent Pcuff readings

\begin{tabular}{|c|c|c|c|c|}
\hline \multirow[b]{2}{*}{ Patient } & \multicolumn{3}{|c|}{ Pcuff at different times } & \multirow[b]{2}{*}{ Pcuff $\left(\mathrm{cmH}_{2} \mathrm{O}\right)$, mean (SD) } \\
\hline & $T_{0}(07 \mathrm{~h} 00)$ & $T_{6}(13 h 00)$ & $T_{12}(19 h 00)$ & \\
\hline 1 & 18 & 26 & 24 & $22.7(4.2)$ \\
\hline 2 & 24 & 18 & 25 & $22.3(3.8)$ \\
\hline 3 & 23 & 22 & 20 & $21.7(1.5)$ \\
\hline 4 & 22 & - & - & 22.0 \\
\hline 5 & 30 & 28 & 26 & $28.0(2.0)$ \\
\hline 6 & 24 & 28 & 26 & $26.0(2.0)$ \\
\hline 7 & 55 & 64 & - & $59.5(6.4)$ \\
\hline 8 & 38 & 26 & 30 & $31.3(6.1)$ \\
\hline 9 & 20 & 12 & 28 & $20.0(8.0)$ \\
\hline 10 & 26 & 28 & 24 & $26.0(2.0)$ \\
\hline 11 & 26 & 30 & 28 & $28.0(2.0)$ \\
\hline 12 & 28 & 28 & 30 & $28.7(1.2)$ \\
\hline 13 & 24 & 24 & 28 & $25.3(2.3)$ \\
\hline 14 & 18 & 18 & 18 & $18.0(0.0)$ \\
\hline 15 & 22 & 24 & 26 & $24.0(2.0)$ \\
\hline 16 & 24 & 26 & 30 & $26.7(3.1)$ \\
\hline 17 & 22 & 20 & 20 & $20.7(1.2)$ \\
\hline 18 & 22 & 19 & 18 & $19.7(2.1)$ \\
\hline 19 & 24 & 28 & 20 & $24.0(4.0)$ \\
\hline 20 & 28 & 30 & 28 & $28.7(1.2)$ \\
\hline 21 & 20 & 16 & - & $18.0(2.8)$ \\
\hline 22 & 25 & 28 & 21 & $24.7(3.5)$ \\
\hline 23 & 23 & 20 & 24 & $22.3(2.1)$ \\
\hline 24 & 30 & 28 & 26 & $28.0(2.0)$ \\
\hline 25 & 24 & 22 & 20 & $22.0(2.0)$ \\
\hline 26 & 18 & 20 & 20 & $19.3(1.2)$ \\
\hline 27 & 26 & 28 & 22 & $25.3(3.1)$ \\
\hline 28 & 24 & 25 & 26 & $25.0(1.0)$ \\
\hline 29 & 22 & 24 & 26 & $24.0(2.0)$ \\
\hline 30 & 20 & 22 & 21 & $21.0(1.0)$ \\
\hline 31 & 26 & 30 & 28 & $28.0(2.0)$ \\
\hline 32 & 21 & 19 & 28 & $22.7(4.7)$ \\
\hline 33 & 28 & 30 & 28 & $28.7(1.2)$ \\
\hline 34 & 24 & 28 & 26 & $26.0(2.0)$ \\
\hline 35 & 38 & 42 & 30 & $36.7(6.1)$ \\
\hline Mean (SD) & $25.3(6.9)$ & $25.9(8.7)$ & $24.8(3.8)$ & $25.6(7.1)$ \\
\hline
\end{tabular}


the ICU were screened for eligibility to be enrolled in the study. Patients were included if they were between 18 and 60 years old, intubated with high-volume, low-pressure cuff tubes, and expected to be mechanically ventilated for more than $24 \mathrm{~h}$. Patients who had anatomical laryngeotracheal abnormalities or who were expected to have a short duration of mechanical ventilation were excluded. Consent was obtained from the patients' next of kin.

The Posey cufflator manometer (Posey Company, USA) was used to record Pcuff at three times during the day. In addition,
Pcuffs were continuously monitored using a Deltran IV disposable pressure transducer (Utah Medical Products Inc, USA). This was transduced onto an independent Nihon Kohden bedside monitor (Nihon Kohden Corp., Japan). A Physiotrac laser level (Edwards Life Sciences, USA) was used to ensure that the transducer was placed in line with cervical spine/cricoid cartilage at $\mathrm{C} 6$.

Patients were positioned with the head end of the bed elevated to $30^{\circ}$. ETT position was confirmed by auscultation and radiology as per the unit protocol. A three-way stopcock was connected to the ETT

\section{Table 2. Continuous Pcuff data}

\begin{tabular}{|c|c|c|c|c|c|c|c|}
\hline \multirow[b]{2}{*}{ Patient } & \multirow[b]{2}{*}{ Time (min) } & \multicolumn{3}{|c|}{ Pressure $\left(\mathrm{cmH}_{2} \mathrm{O}\right)$, mean (SD) } & \multicolumn{3}{|c|}{ Time at each pressure level (maximum) (\%) } \\
\hline & & Maximum & Minimum & Mean & $\begin{array}{l}<20 \\
\mathrm{CmH}_{2} \mathrm{O}\end{array}$ & $\begin{array}{l}20-30 \\
\mathrm{CmH}_{2} \mathrm{O}\end{array}$ & $\begin{array}{l}>30 \\
\mathrm{cmH}_{2} \mathrm{O}\end{array}$ \\
\hline 1 & 670 & $23.2(4.4)$ & $12.8(4.6)$ & $22.2(4.4)$ & 6.8 & 88.7 & 4.5 \\
\hline 2 & 720 & $21.5(7.9)$ & $14.3(4.6)$ & $19.9(5.5)$ & 47.6 & 43.4 & 9.0 \\
\hline 3 & 700 & $22.2(7.7)$ & $13.3(3.9)$ & $20.1(4.7)$ & 38.7 & 51.8 & 9.5 \\
\hline 4 & 135 & $27.1(18.2)$ & $13.4(9.1)$ & $23.2(9.8)$ & 57.1 & 28.6 & 14.3 \\
\hline 5 & 720 & $29.7(4.5)$ & $25.8(4.4)$ & $29.2(4.3)$ & 1.4 & 65.0 & 33.6 \\
\hline 6 & 720 & $28.5(5.3)$ & $24.7(5.1)$ & $28.0(4.9)$ & 14.5 & 49.0 & 36.6 \\
\hline 7 & 450 & $67.4(6.0)$ & $63.8(5.4)$ & $66.8(5.8)$ & 0.0 & 0.0 & 100.0 \\
\hline 8 & 715 & $35.3(5.5)$ & $27.0(4.9)$ & $34.8(5.5)$ & 0.0 & 16.9 & 83.1 \\
\hline 9 & 720 & $24.9(10.8)$ & $19.7(5.8)$ & $23.7(8.4)$ & 42.1 & 33.1 & 24.8 \\
\hline 10 & 720 & $28.1(5.1)$ & $26.1(4.7)$ & $27.8(5.0)$ & 0.0 & 86.9 & 13.1 \\
\hline 11 & 715 & $30.8(4.8)$ & $25.3(3.0)$ & $29.9(4.4)$ & 0.0 & 56.9 & 43.1 \\
\hline 12 & 720 & $29.2(3.8)$ & $25.5(2.6)$ & $28.8(3.8)$ & 0.0 & 72.4 & 27.6 \\
\hline 13 & 590 & $26.6(4.8)$ & $25.0(3.8)$ & $26.4(4.6)$ & 0.8 & 79.0 & 20.2 \\
\hline 14 & 720 & $16.6(2.5)$ & $14.3(1.9)$ & $16.3(2.5)$ & 91.0 & 9.0 & 0.0 \\
\hline 15 & 715 & $23.6(4.7)$ & $21.3(3.0)$ & $23.2(3.7)$ & 12.5 & 81.9 & 5.6 \\
\hline 16 & 720 & $29.6(7.6)$ & $24.8(4.4)$ & $28.8(6.3)$ & 0.0 & 78.6 & 21.4 \\
\hline 17 & 720 & $25.1(5.8)$ & $20.1(3.5)$ & $24.6(5.3)$ & 2.8 & 89.7 & 7.6 \\
\hline 18 & 720 & $24.2(6.1)$ & $18.7(2.5)$ & $23.3(4.8)$ & 14.5 & 73.8 & 11.7 \\
\hline 19 & 710 & $27.9(5.4)$ & $18.1(6.6)$ & $26.5(5.4)$ & 0.0 & 80.4 & 19.6 \\
\hline 20 & 720 & $28.4(5.1)$ & $26.4(4.7)$ & $28.0(5.0)$ & 0.0 & 85.5 & 14.5 \\
\hline 21 & 390 & $20.4(4.1)$ & $11.3(4.5)$ & $18.0(3.0)$ & 44.3 & 54.4 & 1.3 \\
\hline 22 & 720 & $27.6(5.5)$ & $18.4(5.8)$ & $26.6(5.1)$ & 0.0 & 81.4 & 18.6 \\
\hline 23 & 705 & $22.2(3.0)$ & $19.2(2.5)$ & $21.7(2.9)$ & 19.0 & 80.3 & 0.7 \\
\hline 24 & 720 & $30.5(4.8)$ & $28.2(4.5)$ & $30.3(4.4)$ & 0.0 & 71.0 & 29.0 \\
\hline 25 & 710 & $24.7(6.8)$ & $22.2(3.1)$ & $24.1(4.9)$ & 0.0 & 90.9 & 9.1 \\
\hline 26 & 710 & $20.2(4.4)$ & $16.4(1.5)$ & $19.7(2.9)$ & 58.7 & 39.9 & 1.4 \\
\hline 27 & 720 & $27.7(6.1)$ & $24.3(5.0)$ & $27.3(5.7)$ & 0.0 & 82.8 & 17.2 \\
\hline 28 & 720 & $29.6(11.3)$ & $21.0(4.3)$ & $27.6(6.6)$ & 0.0 & 75.2 & 24.8 \\
\hline 29 & 720 & $23.7(4.7)$ & $21.3(3.0)$ & $23.3(3.7)$ & 10.4 & 84.0 & 5.6 \\
\hline 30 & 580 & 21.9 (3.8) & $16.4(3.1)$ & 20.9 (3.6) & 19.5 & 76.3 & 4.2 \\
\hline 31 & 720 & $29.9(5.3)$ & $17.5(3.8)$ & $28.7(4.3)$ & 0.0 & 59.3 & 40.7 \\
\hline 32 & 475 & $25.6(4.8)$ & $20.1(2.9)$ & $24.7(4.7)$ & 0.0 & 88.5 & 11.5 \\
\hline 33 & 710 & $28.7(4.0)$ & $24.1(3.4)$ & $28.2(3.9)$ & 0.0 & 82.5 & 17.5 \\
\hline 34 & 700 & $31.5(8.3)$ & $27.1(5.4)$ & $30.7(8.0)$ & 0.0 & 62.4 & 37.6 \\
\hline 35 & 710 & $34.3(4.1)$ & $27.0(4.4)$ & $33.9(4.2)$ & 0.0 & 10.5 & 89.5 \\
\hline Mean & 667 & $27.4(9.28)$ & $22.1(8.7)$ & $26.6(8.7)$ & 13 & 64 & 23 \\
\hline
\end{tabular}


cuff to allow for an interchange between intermittent and continuous recordings.

Each patient was monitored for a period of $12 \mathrm{~h}$. Intermittent Pcuff was recorded in $\mathrm{CmH}_{2} \mathrm{O}$ at three intervals using the Posey cufflator. The three readings were taken at the beginning $\left(T_{0}\right)$, middle $\left(T_{6}\right)$ and end $\left(T_{12}\right)$ of the study period (Table 1). Continuous Pcuff was displayed on the monitor screen and recorded on the monitor at 1-min intervals. The maximum, minimum and mean pressures were recorded. These data were later manually extracted and recorded at 5-min intervals. Continuous Pcuff was measured in $\mathrm{mmHg}$ and converted to $\mathrm{cmH}_{2} \mathrm{O}$. The continuous Pcuff measurements were assessed as being in one of three groups: low-pressure range $\left(<20 \mathrm{cmH}_{2} \mathrm{O}\right)$, target pressure range $\left(20-30 \mathrm{cmH}_{2} \mathrm{O}\right)$ and high-pressure range $\left(>30 \mathrm{cmH}_{2} \mathrm{O}\right.$ ) (Table 2).

ICU staff were blinded to both the intermittent and continuous readings measured by the principal investigator. ICU staff were allowed to check and adjust Pcuff if necessary as per the unit protocol, which dictated an 8-hourly measurement using the mechanical manometer.

The principal investigator also recorded any events that were likely to alter Pcuff, noting the time at which these occurred, including adjustment of Pcuff by staff, suctioning, patient coughing or struggling, movement of head only and/or whole body, and changes in position for procedures.

The Pcuff readings collected were analysed using a signed-rank test for paired analysis to compare values for the same patient. The test was also used to determine whether the continuous readings identified significant adverse events. Variation in endotracheal Pcuff was expressed as interquartile ranges and shown graphically for both methods over time. Pearson's correlation was also used to compare the intermittent and continuous readings at the same time.

\section{Results}

Thirty-five critically ill adult patients were enrolled, of whom 19 (54.3\%) were male. Mean age was 34 (range $18-60$ ) years. A total of 29 of the subjects were studied for the entire study period. The mean time of study of the group was $667(135-720) \mathrm{min}$. Monitoring was discontinued early in 6 patients: 3 patients were taken to theatre, 1 patient died, 1 patient was extubated and 1 was restless and ICU staff felt the patient should be removed from the study as it was affecting patient care.
Table 1 reflects the data from the intermittent readings from all patients. Only maximum readings were recorded. The mean (standard deviation (SD)) Pcuff of all patients for $\mathrm{T}_{0}$ was 25.3 (6.9) $\mathrm{cmH}_{2} \mathrm{O}$; for $\mathrm{T}_{6} 25.9$ (8.7) $\mathrm{cmH}_{2} \mathrm{O}$ and for $\mathrm{T}_{12} 24.8$ (3.8) $\mathrm{cmH}_{2} \mathrm{O}$. The overall mean (SD) for all readings was $25.6(7.1) \mathrm{cmH}_{2} \mathrm{O}$. Overall, $12 \%$ of the

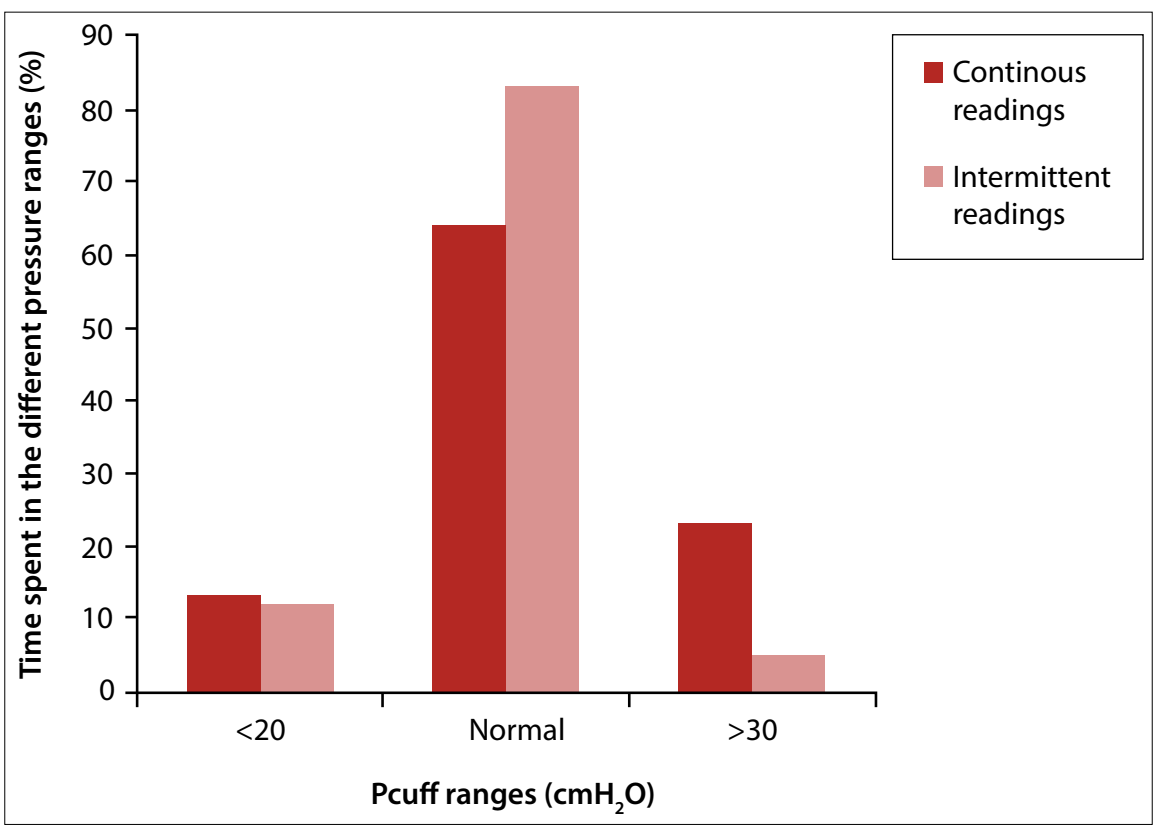

Fig. 1. Continuous v. intermittent readings in the different ranges. (Pcuff = cuff pressure.)

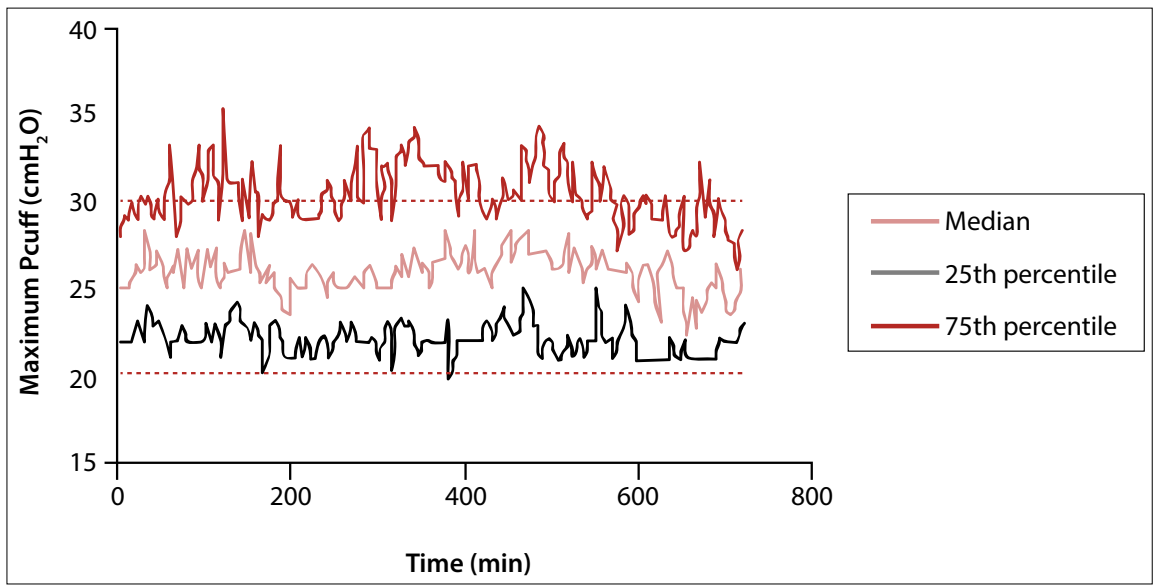

Fig. 2. Interquartile range of maximum Pcuffs for continuous measurement readings. (Pcuff = cuff pressure.)

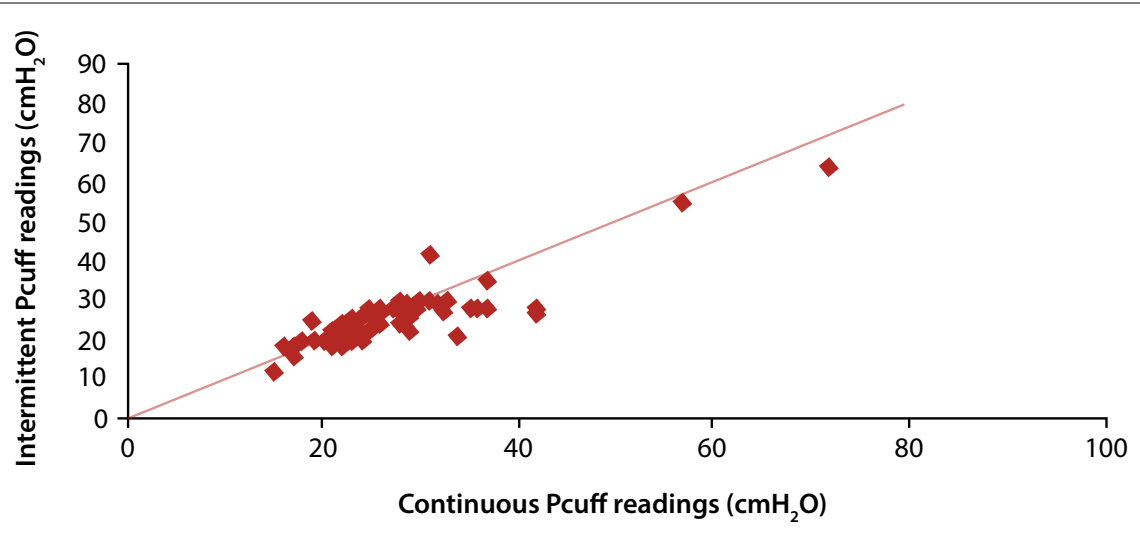

Fig. 3. Correlation between intermittent and continuous readings at the same time $(r=0.87)$. (Pcuff = cuff pressure.) 
time was spent in the low-pressure range $\left(<20 \mathrm{cmH}_{2} \mathrm{O}\right), 83 \%$ in the target pressure range $\left(20-30 \mathrm{cmH}_{2} \mathrm{O}\right)$ and $5 \%$ in the highpressure range (>30 $\left.\mathrm{cmH}_{2} \mathrm{O}\right)$ (Fig. 1).

Table 2 reflects the data from the continuous readings of all patients. The maximum, minimum and mean pressures were recorded and analysed. The mean (SD) maximum Pcuff was 27.4 (9.3) $\mathrm{cmH}_{2} \mathrm{O}$, minimum 22.1 (8.7) $\mathrm{cmH}_{2} \mathrm{O}$, and mean 26.6 (8.7) $\mathrm{cmH}_{2} \mathrm{O}$. The median values for each of the three sets of data were 26, 21 and $25 \mathrm{cmH}_{2} \mathrm{O}$, respectively. The group mean (SD) Pcuff was 26.6 (8.7) $\mathrm{cmH}_{2} \mathrm{O}$ (median $25 \mathrm{cmH}_{2} \mathrm{O}$ ) for continuous readings. Overall, $13 \%$ of the time was spent in the low-pressure range, $64 \%$ in the target pressure range, and $23 \%$ in the high-pressure range (Fig. 1).
A total of 588 events causing alterations in Pcuffs was recorded for the entire patient group over the whole observation period. The average number of events per hour per patient monitored was 1.5 (range 0.7 - 3.0). An increase in pressure resulted from $85 \%$ of the events and a drop in pressure from $15 \%$. Table 3 reflects the distribution of the events that occurred. The most frequently encountered events that caused pressure changes were body movement, coughing, head movement and suctioning.

Fig. 2 illustrates the variability of the data from the continuously monitored readings expressed as the interquartile range using the maximum Pcuffs recorded. The variability in the high-pressure range $\left(>30 \mathrm{cmH}_{2} \mathrm{O}\right)$ was notably greater. Pearson's correlation

Table 3. Distribution of events

\begin{tabular}{|c|c|c|c|}
\hline Event & Frequency & $\%$ & Pcuff range $\left(\mathrm{cmH}_{2} \mathrm{O}\right)$ \\
\hline Body movement & 154 & 26.19 & $12-68$ \\
\hline Patient coughing & 118 & 20.07 & $11-88$ \\
\hline $\begin{array}{l}\text { Head movement only, } \\
\text { i.e. sideways or upwards }\end{array}$ & 113 & 19.22 & $11-94$ \\
\hline Suctioning & 55 & 9.35 & $12-76$ \\
\hline $\begin{array}{l}\text { Patient bathed, including turning } \\
\text { sideways }\end{array}$ & 39 & 6.63 & $16-62$ \\
\hline Ventilation changes & 22 & 3.74 & $14-39$ \\
\hline Unknown or unrecognised event & 21 & 3.57 & $15-25$ \\
\hline Attempting to talk & 17 & 2.89 & $15-45$ \\
\hline Positioned flat for procedures & 17 & 2.89 & $19-54$ \\
\hline Turning of patient by ICU personnel & 10 & 1.70 & $31-58$ \\
\hline Strapping tube & 8 & 1.36 & $19-44$ \\
\hline Tube biting by patient & 5 & 0.85 & $29-61$ \\
\hline Nasogastric tube insertion & 4 & 0.68 & $20-44$ \\
\hline Abnormal breathing pattern/gasping & 1 & 0.17 & 26 \\
\hline Patient died & 1 & 0.17 & 17 \\
\hline Physiotherapy & 1 & 0.17 & $40-55$ \\
\hline Resuscitation & 1 & 0.17 & $30-41$ \\
\hline Wound dressing & 1 & 0.17 & $17-18$ \\
\hline Total events & 588 & 100 & - \\
\hline
\end{tabular}

(Fig. 3) showed good correlation between the intermittent and continuous readings taken at the same time $(r=0.87)$.

Fig. 1 represents the percentage of time in each of the three pressure ranges for the intermittent and continuous readings.

\section{Discussion}

Continuous monitoring of Pcuff indicated that endotracheal Pcuff varies extensively during mechanical ventilation in critically ill patients, both between patients and in individual patients. However, the intermittent measurements showed minimal variation. The study monitored Pcuffs continuously for $12 \mathrm{~h}$ in 35 patients. Several studies have reported important variations in endotracheal Pcuff in ICU patients. ${ }^{[1,21,23]}$ However, these studies differ in that they only recorded Pcuffs intermittently, ranging from every 3 to $8 \mathrm{~h}$.

\section{Continuous measurements}

Pcuff was monitored continuously for a period of $12 \mathrm{~h}$. The Pcuffs for $64 \%$ of the study time for all patients were within the target recommended range $\left(20-30 \mathrm{cmH}_{2} \mathrm{O}\right)$ for the entire data collection time. Table 4 compares our study with previous studies and shows the results to be consistent.

A total of $23 \%$ of the Pcuff measurements was $<20 \quad \mathrm{cmH}_{2} \mathrm{O}$, similar to the $30 \%$ reported by Sole et al. ${ }^{[2]}$ (Table 4). Nseir et al. ${ }^{[1]]}$ demonstrated that underinflation of Pcuff increases with time. This concurs with the present study, as nine patients had gradually decreasing pressures throughout the study. Other studies have also noted a decrease in Pcuff over time. ${ }^{[2,24,25]}$ This decrease may be due to air escaping from the ETT cuff or an increasing airway pressure. Episodes of low pressure may increase the risk for aspiration and ventilator-associated pneumonia. ${ }^{[9,14,26]}$

In the present study, $13 \%$ of Pcuff readings were $>30 \mathrm{cmH}_{2} \mathrm{O}$. This is similar to the findings by other researchers, as

Table 4. Composite results for normal ranges for studies looking at continuous measurements

\begin{tabular}{lllllll}
\hline Reference & $\boldsymbol{n}$ & $\begin{array}{l}\text { Period } \\
\text { monitored }(\mathbf{h})\end{array}$ & $\begin{array}{l}\text { Normal pressure } \\
\text { range }\left(\mathbf{c m H}_{\mathbf{2}} \mathbf{O}\right)\end{array}$ & $\begin{array}{l}\text { Patients in normal } \\
\text { range (\%), mean (SD) }\end{array}$ & $\begin{array}{l}\text { Patients below normal } \\
\text { range (\%), mean (SD) }\end{array}$ & $\begin{array}{l}\text { Patients above normal } \\
\text { range (\%), mean (SD) }\end{array}$ \\
\hline Sole et al. ${ }^{[2]]}$ & 10 & 12 & $20-30$ & 54 & 30 & 16 \\
Nseir et al. ${ }^{[1]}$ & 101 & 8 & $20-30$ & $75(26)$ & $13(20)$ & $11(21)$ \\
Duguet et al. ${ }^{[2]}$ & 9 & 24 & $15-28$ & $56(36)$ & $15(17)$ & $29(25)$ \\
Current study & 35 & 12 & $20-30$ & $64(27)$ & $23(18)$ & $13(26)$
\end{tabular}


reflected in Table 4. The exception was Duguet et al. ${ }^{\left[{ }^{[27]}\right.}$ who showed a higher rate of time spent above $30 \mathrm{cmH}_{2} \mathrm{O}$. Most increases in Pcuff were associated with patient coughing, suctioning and head movement; however, these spikes in pressure did not last for more than $5 \mathrm{~min}$, with the pressure usually returning to baseline or a slightly higher level $\left(\sim 2 \mathrm{cmH}_{2} \mathrm{O}\right)$. Other increases in pressure were due to weaning from sedation and mechanical ventilation. In these cases, the changes lasted for longer periods. Positioning of patients for procedures and changing of neck position by the patient seemed to increase Pcuff for longer periods. This is supported by findings from other studies. ${ }^{[3,10]}$ We did not specifically look for the numerous complications of cuff overinflation in our patients.

\section{Intermittent measurements}

Intermittent Pcuff measurement results reflected a minor variation in Pcuff. Pcuffs in our study were within the accepted range for $83 \%$ of the study time. This would suggest a high concordance with the recommended range. As these were merely intermittent measurements, no conclusions could be drawn about pressure variations between the measurements. To do this, we looked at the continuous measurements between the intermittent readings to highlight the variations in Pcuff.

\section{Intermittent v. continuous measurements}

Considering intermittent measurements only, 24 of 35 patients had their Pcuff within the range for the entire study. This was not the case when compared with continuous readings, where variations in Pcuff were demonstrated below the recommended range in $37 \%$ of patients and above the range in $77 \%$ of patients. This showed that many pressure variations were missed during intermittent recording, which may have lead to underinflation or overinflation not being detected.

In an attempt to compare intermittent and continuous measurements taken at the same time, a good correlation $(r=0.87)$ between the two measurements was demonstrated (Fig. 3). This implies that the measurement techniques for the two were consistent. Differences were therefore not due to the techniques.

\section{Study limitations}

Pcuff was monitored continuously for $12 \mathrm{~h}$, recorded on the monitor at 1-min intervals, with only the 5-min readings being analysed. Computer software for more frequent analysis was not available. Five-minute readings were therefore manually extracted. Smaller time intervals may have indicated more variations.

Pcuff was not adjusted to a fixed absolute baseline pressure. Any reading between $20 \mathrm{cmH}_{2} \mathrm{O}$ and $30 \mathrm{cmH}_{2} \mathrm{O}$ was accepted. Confounders such as sedation, neuromuscular blocking drugs, changes in ventilator parameters and age-related pressure changes were not considered.

\section{Conclusion}

Continuous monitoring of Pcuff indicated that endotracheal Pcuff varies extensively during mechanical ventilation in critically ill patients, such variation being noted both between patients and in individual patients. Variations in an individual patient occur both during intrinsic patient activities and during activities of ICU personnel as part of routine patient maintenance. Intermittent monitoring may not detect these variations.

Continuous monitoring of Pcuff during mechanical ventilation in ICUs is therefore recommended for all patients. Where this is not possible, intermittent monitoring should be performed more frequently than thrice daily. Rechecking the Pcuff after any event that may interfere with the ETT should further complement this. Pcuff should be clearly documented as part of the patient monitoring chart. Where pressures are deemed to be too high or too low, these should be appropriately adjusted and documented as such. It is recommended that a pressure range of $20-30 \mathrm{cmH}_{2} \mathrm{O}$ still be used as the target range. The role of self-adjusting pressure devices, although needing further exploration, holds much promise.

\section{References}

1. Bernhard WN, Yost L, Joynes D, Cothalis S, Turndorf H. Intracuff pressures in endotracheal and tracheostomy tubes: Related cuff physical characteristics. Chest 1985;87(6):720-725.

2. Jaber S, Amraoui J, Lefrant JY, et al. Clinical practice and risk factors for immediate complications Care Med 2006;34(9):2355-2361. [http://dx.doi.org/10.1097/01.CCM.0000233879.58720.87]

3. Brimacombe J, Keller C, Giampalmo M, Sparr HJ, Berry A. Direct measurement of mucosal pressures exerted by cuff and non-cuff portions of tracheal tubes with different cuff volumes and head and neck positions. Br J Anaesth 1999;82(5):708-711. [http://dx.doi.org/10.1093/bja/82.5.708]

4. Lewis FR Jr, Schiobohm RM, Thomas AN. Prevention of complications from prolonged tracheal intubation. Am J Surg 1978;15(3):452-457.

5. Wain JC. Postintubation tracheal stenosis. Chest Surg Clin N Am 2003;13(2):231-246.

6. Fan CM, Ko PC, Tsai KC, et al. Tracheal rupture complicating emergent endotracheal intubation. Am J Emerg Med 2004;22(4):289-293. [http://dx.doi.org/10.1016/j.ajem.2004.04.012]

7. Mooty RC, Rath P, Self M, et al. Review of tracheo-esophageal fistula associated with endotracheal intubation. J Surg Educ 2007;64(4):237-240. [http://dx.doi.org/10.1016/j.jsurg.2007.05.004]

8. El-Orbany M, Salem MR. Endotracheal tube cuffleaks: Causes, consequences, and management Anesth Analg 2013;117(2):428-434. [http://dx.doi.org/10.1213/ANE.0b013e318292ee21]

9. Rello J, Soñora R, Jubert P, Artigas A, Rue M, Valles J. Pneumonia in intubated patients: Core of respiratory airway care. Am J Respir Crit Care Med 1996;154(1):111-115.

10. Inoue S, Takauchi $Y$, Kuro M, Ninaga H. Effects of changes in head and neck position on a tracheal tube cuff. Masui 1998;47(9):1069-1072.

11. Nseir $\mathrm{S}$, Brisson $\mathrm{H}$, Marquette $\mathrm{CH}$, et al. Variations in endotracheal cuff pressure in intubated critically ill patients: Prevalence and risk factors. Eur J Anaesthesiol 2009;26(3):229-234.

12. Atlas GM. A mathematical model of differential tracheal tube cuff pressure: Effects of diffusion and temperature. J Clin Monit Comput 2005;19(6):415-425. [http://dx.doi.org/10.1007/s10877005-1626-5]

13. Mehta S. Endotracheal cuff pressure. BMJ (Clin Res Ed) 1984;288(6432):1763-1764.

14. Diaz E, Rodriguez AH, Rello J. Ventilator-associated pneumonia: Issues related to the artificial airway. Respir Care 2005;50(7):900-906.

15. Niederman M, Craven D, American Thoracic Society, Infectious Diseases Society of America. Guidelines for the management of adults with hospital-acquired, ventilator-associated, and healthcare-associated pneumonia. Am J Respir Crit Care Med 2005;171(4):388-416. [http:// dx.doi.org/10.1164/rccm.200405-644ST]

16. Dullenkopf A, Gerber A, Weiss M. Fluid leakage past tracheal tube cuffs: Evaluation of the new Microcuff endotracheal tube. Intensive Care Med 2003;29(10):1849-1853. [http://dx.doi. org/10.1007/s00134-003-1933-6]

17. Braz JR, Navarro LH, Takata IH, Nascimento Júnior P. Endotracheal tube cuff pressure: Need for precise measurement. Sao Paulo Med J 1999;117(6):243-247.

18. Vyas $D$, Inwereqbu K, Pittard A. Measurement of tracheal tube cuff pressure in critical care Anaesthesia 2002;57(3):275-277. [http://dx.doi.org/10.1046/j.1365-2044.2002.2404_3.x]

19. Jaber S, El Kamel M, Chanques G, et al. Endotracheal tube cuff pressure in intensive care unit: The need for pressure measurement. Intensive Care Med 2007;33(5):917-918. [http://dx.doi. org/10.1007/s00134-007-0594-2]

20. Sole ML, Aragon D, Bennett M, Johnson RL. Continuous measurement of endotracheal tube cuff pressure: How difficult can it be? AACN Adv Crit Care 2008;19(2):235-243. [http://dx.doi. org/10.1097/01.AACN.0000318126.79630.76]

21. Sole ML, Penoyer DA, Su X, et al. Assessment of endotracheal cuff pressure by continuous monitoring: A pilot study. Am J Crit Care 2009;18(2):133-143. [http://dx.doi.org/10.4037/ajcc2009441]

22. Efrati S, Deutsch I, Gurman GM, Noff M, Conti G. Tracheal pressure and endotracheal tube obstruction can be detected by continuous cuff pressure monitoring: In vitro pilot study. obstruction can be detected by continuous cuff pressure monitoring: In vitro pilot study.
Intensive Care Med 2010;36(6):984-990. [http://dx.doi.org/10.1007/s00134-010-1835-3]

23. Valencia $M$, Ferrer $M$, Farre $R$, et al. An automatic control of tracheal tube cuff pressure in ventilated patients in semicumbent position: A randomised trial. Crit Care Med 2007;35(6):1543-1548. [http://dx.doi.org/10.1097/01.CCM.0000266686.95843.7D]

24. Sole ML, Combs SM, Willis J. Changes in endotracheal cuff pressures over time [abstract]. Crit Care Med 2003;31(Suppl):144.

25. Fernandez E, Blanch I, Mancebo J, Bonsomy N, Artigas A. Endotracheal tube cuff pressure assessment pitfalls of finger estimation and need for objective measurement. Crit Care Med 1990;18(12):1423-1426.

26. Lorente L, Lecuona M, Jimenez A, et al. Continuous endotracheal tube cuff pressure control system protects against ventilator-associated pneumonia. Crit Care 2014;18(2):R77. [http:// dx.doi.org/10.1186/cc13837]

27. Duguet A, D’Amico L, Biondi G, Prodanovic H, Gonzalez-Bermejo J, Similowski T. Control of tracheal cuff pressure: A pilot study using a pneumatic device. Intensive Care Med 2007;33(1):128-132. [http://dx.doi.org/10.1007/s00134-006-0417-x] 